\title{
Multidimensional systems and signal processing editorial
}

\author{
N. K. Bose
}

Published online: 27 May 2009

(C) Springer Science+Business Media, LLC 2009

The previous Issue was devoted to the topic "Image and video processing for wireless sensor networks", guest edited by E.Y. Lam, K.S. Lui and V.W.L. Tam. The popularity of the topic is underscored by a journal entitled "Wireless Sensor Network" (Website: http://www. scirp.org/journal/wsn), where readers may find other papers concerned with advancement of wireless sensor network and applications.

I wish to bring out some changes in the day-to-day operation of our journal that was communicated to me recently. Ms. Jeyel Tecson is the new support contact for the journal. Henceforth please direct any queries and requests regarding the Editorial Manager (EM) system to her instead of to Ms. Marife Tiangco, who was the previous JEO Assistant. You can contact her through Jeyel.Tecson@springer.com always and her fax number is +632 3250601. Editorial Assistant Ms. Emma Kalb, who is with Springer Science and Business Media at the New York Office (233 Spring St. New York, NY 10013, United States), will take over the responsibilities of Ms. Jill Strathdee, who left Springer towards the end of April. Her coordinates are Emma.Kalb@springer.com with tel +1 (212) 460-1643 and fax +1 (212) 4630742. Emma Kalb will, if necessary, work with Laura Lander (Laura.Lander@ springer.com) and both will be under the direct supervision of Ms. Jennifer Evans, who is known to most for her many years of experience with our journal.

While I write this Editorial, I am reminded of the plans for summer travels to several conferences and workshops of interest that may be meeting-points for several of us. To that list, I add the summer schools on (a) computer algebra and szyzygies at Sophus-Lie Konferenzzentrum at Norway from 15 to 19 June, 2009, (b) algebraic analysis and computer algebra (AACA'09) at Linz, Austria from July 13 to 17, 2009 and international workshops on (1) symbolic-numeric computation (SNC 2009) at Kobe, Japan from 3 to 5 August, 2009 and (2) computer algebra in scientific computing (CASC 2009) in Kobe, Japan from 13 to 17 September 2009. For a blend of theory and practice, there are also the International Conference on Condition Monitoring and Machinery Failure Prevention Technologies (CM 2009

N. K. Bose $(\varangle)$

Department of Electrical Engineering, The Pennsylvania State University,

Electrical Engineering East, University Park, PA 16802, USA

e-mail: bkn@engr.psu.edu 
and MFPT 2009) at Dublin, Ireland, from 23 to 25 June 2009 and, of course, NDS'09 in Thessaloniki, Greece from 29 June to 01 July 2009 (see earlier announcements for this).

No matter, where you go, do have a most wonderful summer and enjoy reading this issue. The next issue will also be devoted to several fine contributed papers that were peer-reviewed and accepted. 